\title{
Proportion of hospital readmissions deemed avoidable: a systematic review
}

\author{
Carl van Walraven MD MSc, Carol Bennett MSc, Alison Jennings MA, Peter C. Austin PhD, Alan J. Forster MD MSc
}

See related commentary by Goldfield at www.cmaj.ca/cgi/doi/10.1503/cmaj.110448

\begin{abstract}
Background: Readmissions to hospital are increasingly being used as an indicator of quality of care. However, this approach is valid only when we know what proportion of readmissions are avoidable. We conducted a systematic review of studies that measured the proportion of readmissions deemed avoidable. We examined how such readmissions were measured and estimated their prevalence.
\end{abstract}

Methods: We searched the MEDLINE and EMBASE databases to identify all studies published from 1966 to July 2010 that reviewed hospital readmissions and that specified how many were classified as avoidable.

Results: Our search strategy identified 34 studies. Three of the studies used combinations of administrative diagnostic codes to determine whether readmissions were avoidable. Criteria used in the remaining studies were subjective.
Most of the studies were conducted at single teaching hospitals, did not consider information from the community or treating physicians, and used only one reviewer to decide whether readmissions were avoidable. The median proportion of readmissions deemed avoidable was $27.1 \%$ but varied from $5 \%$ to $79 \%$. Three study-level factors (teaching status of hospital, whether all diagnoses or only some were considered, and length of follow-up) were significantly associated with the proportion of admissions deemed to be avoidable and explained some, but not all, of the heterogeneity between the studies.

Interpretation: All but three of the studies used subjective criteria to determine whether readmissions were avoidable. Study methods had notable deficits and varied extensively, as did the proportion of readmissions deemed avoidable. The true proportion of hospital readmissions that are potentially avoidable remains unclear.
I $\mathrm{n}$ most instances, unplanned readmissions to hospital indicate bad health outcomes for patients. Sometimes they are due to a medical error or the provision of suboptimal patient care. Other times, they are unavoidable because they are due to the development of new conditions or the deterioration of refractory, severe chronic conditions.

Hospital readmissions are frequently used to gauge patient care. Many organizations use them as a metric for institutional or regional quality of care. ${ }^{1}$ The widespread public reporting of hospital readmissions and their use in considerations for funding implicitly suggest a belief that readmissions indicate the quality of care provided by particular physicians and institutions.

The validity of hospital readmissions as an indicator of quality of care depends on the extent that readmissions are avoidable. As the proportion of readmissions deemed to be avoidable decreases, the effort and expense required to avoid one readmission will increase. This decrease in avoidable admissions will also dilute the relation between the overall readmission rate and quality of care. There- fore, it is important to know the proportion of hospital readmissions that are avoidable.

We conducted a systematic review of studies that measured the proportion of readmissions that were avoidable. We examined how such readmissions were measured and estimated their prevalence.

\section{Methods}

\section{Literature search}

We consulted a local information scientist to develop a search strategy to identify studies that measured the proportion of readmissions deemed avoidable (Appendix 1, available at www.cmaj .ca/cgi/content/full/cmaj.101860/DC1). We applied this strategy to search the MEDLINE and EMBASE databases for English-language papers published from 1966 to July 2010. Fulltext versions of citations were retrieved for complete review if they specified that hospital readmissions were counted; and the title or abstract used any term(s) indicating that readmissions were classified as avoidable (or "preventable,"
Competing interests: None declared.

This article has been peer reviewed.

Correspondence to: Dr. Carl van Walraven, carlv@ohri.ca

CMAJ 2011. DOI:10.1503 /cmaj.101860 
"needless" or "unnecessary") or not.

We included studies if they included a population of hospital readmissions and if they counted the number of readmissions that they classified as avoidable. The references of all included studies were reviewed to identify other eligible analyses. In addition, we reviewed the links of all PubMed "related articles" of each included study.

\section{Data abstraction}

Data abstracted from each study included basic study information (publication year, journal); inclusion criteria for, and numbers of, index admissions and readmissions; follow-up period after index admission within which readmissions were considered; whether or not information from potential sources (e.g., index admission, clinic visits between index and readmission, readmission, interviews with treating physicians or nurses, interviews with patients or families) were used when determining avoidability of readmissions; and the criteria required for readmissions to be classified as avoidable.

We abstracted the number of reviewers used (per readmission) and whether or not readmissions attributable to specific groups or factors were considered avoidable. We searched for these groups or factors in the methods section and in descriptions of avoidable readmissions in each study and classified them as treating physician (e.g., medical errors, omissions of care); nurse (e.g., inadequate dressings); patient (e.g., noncompliance with therapy); social (e.g., inability of family to care for patient in community); and system (e.g., home care unavailable).

Two of us (C.B. and A.J.) independently abstracted data from a random sample of 10 studies to compare agreement and implement abstraction criteria to harmonize abstraction. Subsequently, a single reviewer (C.B. or A.J.) abstracted data from all of the remaining studies. All abstractions were reviewed and confirmed by the lead author (C.v.W.).

\section{Statistical analysis}

Basic descriptive statistics for each study were calculated. To explore study heterogeneity, we created a meta-regression model that measured the association of study factors with the proportion of readmissions deemed avoidable. The three studies that used administrative data to identify avoidable readmissions were methodologically distinct from the others and did not define many of the variables required for the meta-regression. We therefore grouped these three studies together and included the remaining studies in the the meta-regression model. Study factors that were not defined were defaulted to null for our model.
Model building used 13 candidate binary variables (e.g., year study was published; use of administrative databases; number of reviewers involved; length of follow-up period; factors included, and sources of information used, in determining avoidability of readmissions; location and type of hospital; type of hospital service to which patients were admitted; and whether or not limited number of diagnoses included). In the models, studies were weighted by the inverse of the variance for the proportion of readmissions deemed avoidable. Ordinal and continuous variables were transformed into binary variables by their median values. This created a model that allowed us to group studies based on values of each independently significant covariate. We used forward selection methods to identify the study factors that had the strongest independent association with the proportion of readmissions deemed avoidable. We limited the regression model to three covariates (about 10 observations per covariate) to avoid overfitting. ${ }^{2}$ To determine goodness of fit, we calculated the Akaike information criterion value for all possible three-variable models.

Studies were grouped based on their values of the binary covariates included in the final meta-

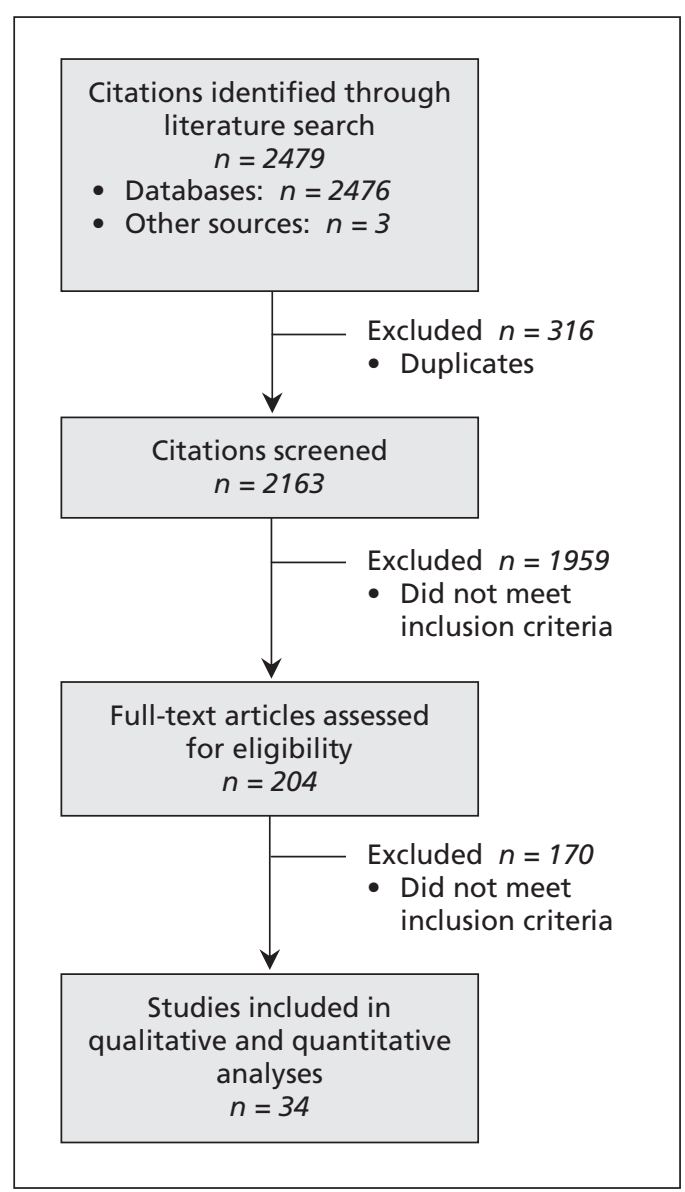

Figure 1: Selection of studies that measured the proportion of hospital readmissions deemed avoidable. 
regression model. To calculate the overall proportion of readmissions deemed avoidable for studies in each group, we weighted studies by the inverse of their variance. ${ }^{3}$ Heterogeneity of results within each group was measured using the Cochran Q and the $I^{2}$ statistics.,.4

\section{Results}

Figure 1 presents the results of our search strategy. After screening 2163 citations, we reviewed the full-text articles of 204 studies. Thirty-four of the studies measured the proportion of hospital readmissions deemed avoidable..$^{5-38}$

A summary of the studies' characteristics appears in Table 1. The included studies were published between 1983 and 2009 (median year 2000). Most of the studies were conducted at single centres; almost two-thirds were conducted primarily in teaching hospitals. Patients were most commonly admitted to medical, surgical and geriatric services. Most of the studies included all readmissions regardless of the diagnosis; four $(12.5 \%)$ restricted readmissions to particular diagnoses, including congestive heart failure, ${ }^{16,38}$ diabetes ${ }^{16}$ obstructive lung disease ${ }^{16}$ and adverse drug reactions. ${ }^{34}$ Half of the studies limited readmissions to those that occurred within three months after discharge. Most of the studies were moderately sized, with a median of 151 readmissions (interquartile range [IQR] 75313). Studies originated primarily from the United Kingdom ${ }^{5,8-10,13-15,21,24-26,31,36-38}$ and the United States. ${ }^{711,12,16-18,2,27,33}$

\section{Criteria used to identify avoidable readmissions}

Criteria used to identify avoidable readmissions varied extensively between the studies (see Table 2 , at the end of the article). Three studies ${ }^{18,27,33}$ used only administrative data in their analyses and classified readmissions based on combinations of diagnostic codes between the index admission and the readmission. For example, in the study by Goldfield and colleagues, all readmissions with a diagnostic code of diabetes for which the index admission had a diagnostic code of myocardial infarction were classified as avoidable. ${ }^{33}$

Criteria used in the rest of the studies fell into one of four general groups. Four studies did not specify the criteria used to classify readmissions, stating that reviewers judged which readmissions were avoidable. ${ }^{12,17,25,26}$ Eleven studies described criteria that were subjective, citing few or no qualifiers or guides for reviewers. ${ }^{6,13,14,16,21,22,24,31,35,37,38}$ Three studies used criteria that focused exclusively on adverse drug reactions. ${ }^{20,34,36}$ Miles and Lowe used methods similar to those in studies of adverse events, with a defined six-point scale to determine whether readmissions were avoidable. ${ }^{20}$

In the fourth group, 13 studies used criteria with several qualifiers provided to define "avoidable," often providing categories for avoidable readmissions. ${ }^{5,7-11,15,19,2,2,28-30,32}$ Several studies within this category were notable: Graham and Livesley classified readmissions into one of five groups, ${ }^{5}$ and their methods were the most commonly repli-

Table 1: Summary of characteristics of 34 studies that measured the proportion of hospital readmissions deemed avoidable

Variable

No. $(\%)$ of studies*

Study characteristics

Year of publication, median (IQR)

2000 (1993-2005)

No. of hospitals per study, median (range)

$1(1-234)$

Conducted at single centre $(n=31) \dagger$

26 (83.9)

Conducted primarily in teaching hospitals $(n=28) \neq$

18 (64.3)

Index admission used as unit of analysis§

19 (55.9)

No. of index admissions, median (IQR) $(n=19)$ **

1289 (743-3050)

Follow-up period for readmission, mo, median (IQR)

$2(1-6)$

No. of readmissions, median (IQR)

$151(75-313)$

Type of patient

Medical

$25(73.5)$

Surgical

$13(38.2)$

Geriatric

$11(32.4)$

Assessment of avoidability $(n=31)+\dagger$

Information used for assessment

Index admission 25 (80.6)

Clinical visits between index admission and $\quad 10(32.3)$

readmission

Readmission

$27(87.1)$

Interviews with physician or nurset†

7 (22.6)

Interviews with patient or familyt†

$9(29.0)$

Groups or factors included in assessment

$\begin{array}{ll}\text { Physician } & 28(90.3)\end{array}$

Nurse 2 (6.5)

Patient 7 (22.6)

Social

$16(51.6)$

System

5 (16.1)

Minimum no. of reviewers, median (range)

$1(1-3)$

One reviewer only

$17(54.8)$

\section{Outcomes}

No. of readmissions deemed avoidable, median (IQR)

$35(17-70)$

$\%$ of readmissions deemed avoidable, median (IQR)

$27.1(14.9-45.6)$

$\%$ of index admissions followed by an avoidable readmission, median (IQR) $(n=19)$

Note: IQR = interquartile range

*Unless stated otherwise.

†Number of included hospitals not stated in three studies. ${ }^{10,22,27}$

¥The teaching status of included hospitals was not stated in six studies. ${ }^{10,18,22,27,30,33}$

$\S$ The unit of analysis was the readmission in the other 15 studies.

$* *$ The denominator comprises the 19 studies in which the unit of analysis was the index admission.

t+Excludes data from the three studies based on administrative databases alone. $18,27,33$ 
cated in other studies; MacDowell and colleagues used an algorithmic method to identify avoidable readmissions; ${ }^{7}$ and Halfon and coauthors provided detailed and specific criteria to determine avoidability stratified by phases of patient care. ${ }^{23}$

Perhaps with the exception of criteria dealing exclusively with adverse drug events, criteria used to identify avoidable readmissions were subjective and left reviewers much room to make decisions regarding whether or not readmissions were avoidable.

We noted large variations between studies in the application of criteria (Table 1). Of the 31 studies that indicated the number of reviewers involved in determining the avoidability of each readmission, most $(17,54.8 \%)$ used only one reviewer; the maximum number was three reviewers per readmission (7 studies, $22.6 \%$ ). Studies varied in the sources of information used to determine avoidability. Most included information abstracted from the medical record of the index admission (25 studies, $80.6 \%$ ) or the readmission (27 studies, $87.1 \%$ ). Information from clinic notes between the index admission and readmission were used in about one-third of the studies. Information from interviews with treating physicians and patients was used in less than one-third of the studies. Finally, studies varied on whether or not readmissions attributable to specific groups or factors were considered avoidable. The most common factors included actions or omissions on the part of treating physicians or hospitals (28 studies, $90.3 \%$ ). All of the other factors, including those attributable to the patient (7 studies, 22.6\%) and social issues (16 studies, $51.6 \%$ ), were much less commonly considered when determining the avoidability of readmissions.

\section{Proportion of readmissions deemed avoidable}

The proportion of readmissions deemed avoidable varied extensively between the studies (Tables 1 and 3). The median unweighted proportion was $27.1 \%$, although the range was $5.0 \%-78.9 \%$ (Figure 2, Table 3). In the 19 studies that used the index admission as the unit of analysis, avoidable readmissions were noted in a median of $2.2 \%$ of discharges (IQR 1.5\%-7.0\%).

Many study-level factors were reported to be associated with the proportion of readmissions deemed avoidable (Table 4). In the univariable analysis, studies that used administrative data had notably higher proportions of avoidable readmissions than studies that used other criteria. Proportions of readmissions deemed avoidable were significantly higher in studies in which patients were from medical services than in studies without such patients or in which patient type was not specified. Studies reporting the lowest proportions of avoidable readmissions included those conducted primarily in teaching hospitals and those that only included avoidable readmissions due to physician factors. Surprisingly, studies that involved more than one reviewer per case had higher proportions of avoidable readmissions than those involving one reviewer.

In the multivariable analysis, the three studylevel factors associated with significantly high proportions of avoidable readmissions (and therefore retained in the model) were limiting of readmissions to those with specific diagnoses, a follow-up period of up to one year after the index admission and having teaching hospitals make up the majority of hospitals in the study (Table 4). This model had the lowest Akaike Information Criterion goodness-of-fit value (658) of all possible three-variable models in our study.

The three factors in our multivariable model explained some of the heterogeneity in the study results. In Figure 2, we grouped studies based on their values for the three binary covariates that made it into the final model (Table 4). Within each group, we calculated the weighted proportion of avoidable readmissions for the group, the Cochran Q value and the $I^{2}$ value. In three combinations of study-level factors, heterogeneity was resolved (Figure 2), but only one of these groups (with the three factors of mostly teaching hospitals, specific diagnoses and readmissions within one year after discharge) contained more than one study. That significant heterogeneity persists after clustering studies based on the most important study-level factors indicates the extensive amount of heterogeneity in these studies.

\section{Interpretation}

Readmissions to hospital are increasingly being used as a quality-of-care measure. They can indicate quality of care, however, only if an important proportion of them are deemed avoidable. In our systematic review, we identified 34 studies that measured the proportion of readmissions deemed avoidable. Subjective criteria and variable methods were used in every study. The proportions of readmissions deemed avoidable varied widely between the studies. This variability makes it difficult to state with any certainty how often readmissions are preventable. Nevertheless, the median proportion of readmissions deemed avoidable $(27.1 \%)$ is certainly lower than the 76\% reported in 2007 by the Medicare Payment Advisory Commission to the US Congress. ${ }^{39}$ Although the variation seen in these studies could reflect true differences in quality of patient care, it also reflects the subjectivity of the 
outcome itself as well as differences in study characteristics, including patient and hospital types included; factors considered in determining avoidability of readmissions; sources of information used to judge avoidable status; and the minimum number of reviewers per case.

Although subjectivity will always exist when determining whether readmissions are avoidable, steps can be taken to minimize resulting error. First, parameters required for reviewing readmis- sions - such as which factors responsible for a readmission (e.g., physician, nurse, patient) are classified as avoidable - need to be clarified. Second, the use of multiple reviewers is essential when dealing with subjective outcomes such as avoidable readmissions. Because the accuracy of reviews is never perfect, the use of multiple reviewers helps ensure that patient classifications are as accurate as possible. Finally, latent class models can be used to analyze multiple reviews

Used administrative databases only
Experton $^{18}$
Friedman $^{27}$
Goldfield $^{33}$
Mostly nonteaching hospitals; all
diagnoses; readmissions $<2.5$ mo
Clarke $^{10}$
Gautam $^{14}$
Halfon $^{23}$
Kirk $^{31}$
Shalchi38
Williams

Mostly teaching hospitals; specific diagnoses; readmissions $<2.5$ mo Ruiz 34

Mostly teaching hospitals; specific diagnoses; readmissions $<1 \mathrm{yr}$ Oddone ${ }^{16}$

Phelan 37

Mostly nonteaching hospitals; all diagnoses; readmissions $<1 \mathrm{yr}$ Graham $^{5}$

Haines-Wood ${ }^{15}$

Jimenez-Puente ${ }^{28}$

Mclnness $^{8}$

Stanley ${ }^{35}$

Mostly nonteaching hospitals; specific diagnoses; readmissions $<1$ yr Madigan $^{22}$

Mostly teaching hospitals; all diagnoses; readmissions $<2.5 \mathrm{mo}$ Balla 32

Courtney ${ }^{26}$

Frankl12

Levy $^{21}$

McKay ${ }^{17}$

Miles 20

Munshi24

Popplewell 6

Sutton 25

Witherington ${ }^{36}$

Mostly teaching hospitals; all diagnoses; readmissions < $1 \mathrm{yr}$ Halfon ${ }^{30}$

Kelly ${ }^{13}$

Kwok ${ }^{19}$

MacDowell $^{7}$

Maurer 29

Vinson ${ }^{11}$

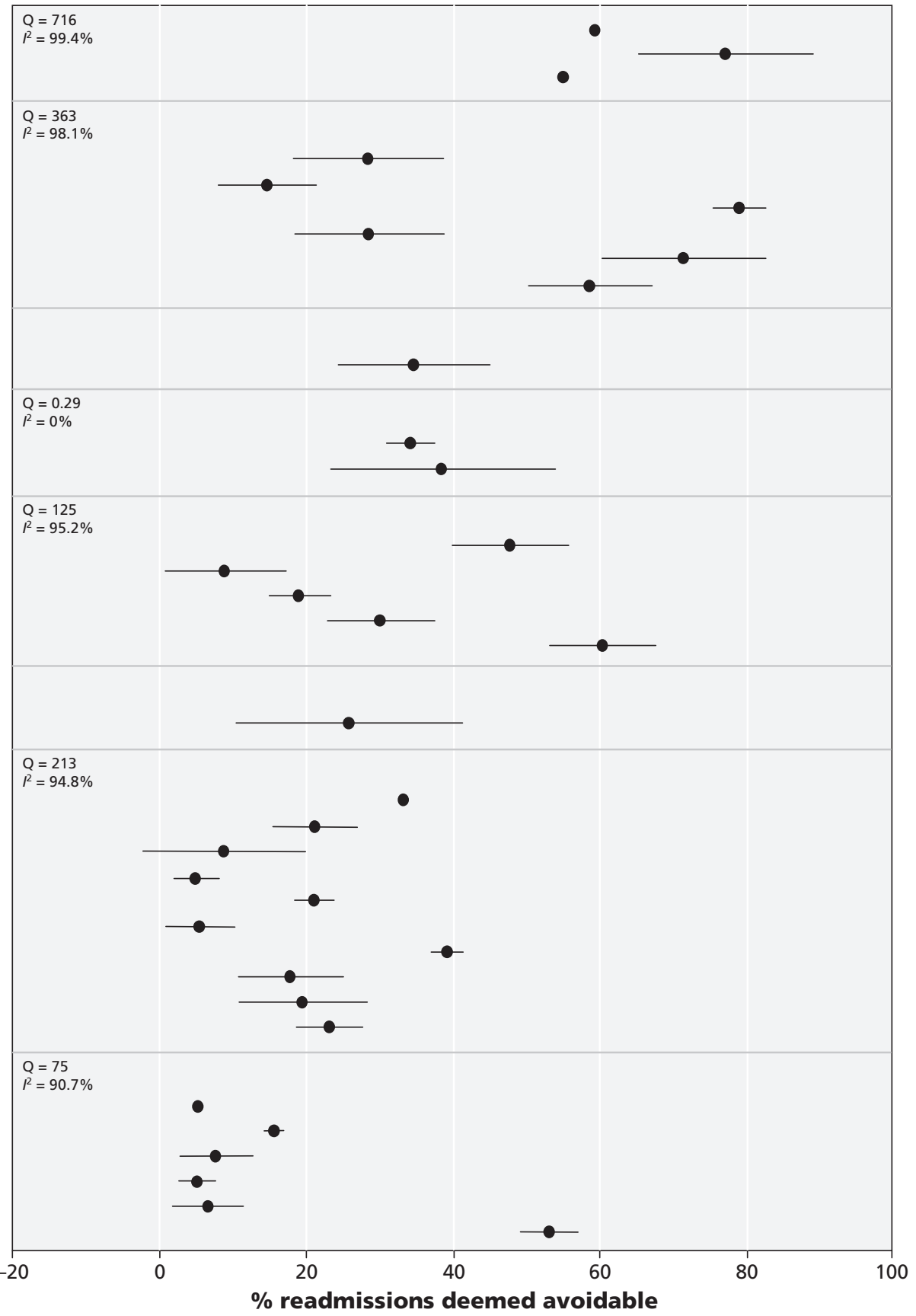

Figure 2: Proportion of hospital readmissions deemed avoidable. Studies are grouped based on the value of study factors with the strongest association with this outcome (Table 4). Error bars $=95 \%$ confidence intervals. 
and generate the probability that each patient truly had an avoidable readmission. ${ }^{40-42} \mathrm{We}$ believe that such models may be useful to classify avoidable readmissions more reliably.

\section{Limitations}

Our study has limitations. First, although we used a clear and sensible search strategy that identified a large number of studies, we may have missed relevant publications. In addition, we limited studies to those published in English. However, given the large number of studies included in our review, it is unlikely that our overall conclusions would change meaningfully if any missed studies were included.

Second, we used transparent meta-regression modelling to identify the most important sources of heterogeneity between studies. Although we limited this model to three covariates to avoid overfitting of the model, significant heterogeneity remained. This finding is not unexpected given the extensive amount of heterogeneity

Table 3: Results of studies included in the meta-analysis

\begin{tabular}{|c|c|c|c|c|}
\hline Study & $\begin{array}{l}\text { No. of index } \\
\text { admissions* }\end{array}$ & $\begin{array}{l}\text { No. of readmissions } \\
\text { ( } \% \text { of index } \\
\text { admissions) }\end{array}$ & $\begin{array}{c}\text { No. }(\%) \text { of } \\
\text { readmissions } \\
\text { deemed avoidable }\end{array}$ & $\begin{array}{l}\% \text { of index admissions } \\
\text { followed by an } \\
\text { avoidable readmission* }\end{array}$ \\
\hline Graham $^{5}$ & - & 153 & $73(47.7)$ & - \\
\hline Popplewell ${ }^{6}$ & 978 & $73 \quad(7.5)$ & $13(17.8)$ & 1.3 \\
\hline MacDowell & - & 78 & $4(5.1)$ & - \\
\hline Mclnness $^{8}$ & - & 153 & $46(30.1)$ & - \\
\hline Williams $^{9}$ & - & 133 & $78(58.6)$ & - \\
\hline Clarke $^{10}$ & - & 74 & $21(28.4)$ & - \\
\hline Vinson $^{11}$ & 140 & $66(47.1)$ & $35(53.0)$ & 25.0 \\
\hline Frankl $^{12}$ & 2626 & $318(12.1)$ & $28(8.8)$ & 1.1 \\
\hline Kelly ${ }^{13}$ & - & 211 & $33(15.6)$ & - \\
\hline Gautam $^{14}$ & 713 & $109(15.3)$ & $16(14.7)$ & 2.2 \\
\hline Haines-Wood ${ }^{15}$ & 84 & $45(53.6)$ & $4 \quad(8.9)$ & 4.8 \\
\hline Oddone $^{16}$ & 1262 & 811 (64.3) & $277(34.2)$ & 21.9 \\
\hline McKay ${ }^{17}$ & 3705 & $289 \quad(7.8)$ & $61(21.1)$ & 1.6 \\
\hline Experton $^{18}$ & 190 & $48(25.3)$ & $37(77.1)$ & 19.5 \\
\hline Kwok $^{19}$ & 1204 & $455(37.8)$ & $35 \quad(7.7)$ & 2.9 \\
\hline Miles $^{20}$ & - & 437 & $24 \quad(5.5)$ & - \\
\hline Levy $^{21}$ & 2484 & $262(10.5)$ & $13(5.0)$ & 0.5 \\
\hline Madigan 22 & 114 & $31(27.2)$ & $8(25.8)$ & 7.0 \\
\hline Halfon $^{23}$ & 3474 & 1115 (32.1) & $59(5.3)$ & 1.7 \\
\hline Munshi $^{24}$ & 3706 & $179 \quad(4.8)$ & $70(39.1)$ & 1.9 \\
\hline Sutton 25 & - & 297 & $58(19.5)$ & - \\
\hline Courtney $^{26}$ & 1914 & $52 \quad(2.7)$ & $11(21.2)$ & 0.6 \\
\hline Friedman $^{27}$ & 345651 & 122015 (35.3) & $67108(55.0)$ & 19.4 \\
\hline Jimenez-Puente ${ }^{28}$ & - & 363 & $69(19.0)$ & - \\
\hline Maurer $^{29}$ & 773 & $151(19.5)$ & $10(6.6)$ & 1.3 \\
\hline Halfon ${ }^{30}$ & - & 494 & $390(78.9)$ & - \\
\hline Kirk $^{31}$ & 1289 & $77 \quad(6.0)$ & $22(28.6)$ & 1.7 \\
\hline Balla $^{32}$ & 1913 & $271(14.2)$ & $90(33.2)$ & 4.7 \\
\hline Goldfield $^{33}$ & 3501142 & 409759 (11.7) & 242991 (59.3) & 6.9 \\
\hline Ruiz $^{34}$ & - & 81 & $28(34.6)$ & - \\
\hline Stanley ${ }^{35}$ & - & 141 & $85(60.3)$ & - \\
\hline Witherington ${ }^{36}$ & - & 108 & $25(23.1)$ & - \\
\hline Phelan ${ }^{37}$ & - & 39 & $15(38.5)$ & - \\
\hline Shalchi ${ }^{38}$ & - & 63 & $45(71.4)$ & - \\
\hline
\end{tabular}


between the studies (Figure 2). In addition, the model's outcome (proportion of readmissions deemed avoidable) will have notable error in it because of the subjectivity involved in the classification of readmissions as avoidable or not. This error will not be captured by the study-level factors in our regression model.

Third, we combined studies from different health care systems. Although some factors contributing to the proportion of avoidable readmissions are likely universal (e.g., incorrect diagnosis), other factors influencing readmission rates that are unique to particular health care systems (e.g., health insurance coverage) will not be captured in our model.

Finally, we were unable to summarize disease-specific proportions of avoidable readmissions, because they were rarely reported in studies that included a broad assortment of diseases.
Future studies would need to address this issue to identify possible diseases that could be targeted for interventions to decrease the risk of avoidable readmissions.

\section{Conclusion}

Our study showed that the proportion of hospital readmissions deemed avoidable has yet to be reliably determined. Furthermore, we found a lack of consensus regarding the methods necessary to judge whether readmissions are avoidable. Given the large variation in the proportion of avoidable readmissions between studies using primary data, "avoidability" cannot accurately be inferred based on diagnostic codes for the index admission and the readmission. Instead, it needs to be determined through a peer-review process in which readmissions are classified as avoidable or not based on expert opinion.

Table 4: Association between study-level factors and proportion of readmissions deemed avoidable in binomial regression models*

\begin{tabular}{|c|c|c|c|c|c|c|}
\hline \multirow[b]{3}{*}{ Study-level factor } & \multicolumn{6}{|c|}{ Weighted overall proportion of readmissions deemed avoidable } \\
\hline & \multicolumn{2}{|c|}{ Unadjusted } & & \multicolumn{2}{|c|}{ Adjusted } & \multirow[b]{2}{*}{$p$ value } \\
\hline & $\begin{array}{l}\text { In studies } \\
\text { with } \\
\text { factor }\end{array}$ & $\begin{array}{l}\text { In studies } \\
\text { without } \\
\text { factor }\end{array}$ & $p$ value & $\begin{array}{l}\text { In studies } \\
\text { with } \\
\text { factor }\end{array}$ & $\begin{array}{l}\text { In studies } \\
\text { without } \\
\text { factor }\end{array}$ & \\
\hline $\begin{array}{l}\text { Used administrative } \\
\text { databases }\end{array}$ & 59.0 & 11.7 & $<0.001$ & - & - & - \\
\hline $\begin{array}{l}\text { Included patients on } \\
\text { medical wardst }\end{array}$ & 59.0 & 20.0 & $<0.001$ & - & - & - \\
\hline Included surgical patients $†$ & 9.3 & 18.0 & $<0.001$ & - & - & - \\
\hline Included geriatric patientst & 9.3 & 18.0 & $<0.001$ & - & - & - \\
\hline$>1$ reviewer & 24.6 & 9.3 & $<0.001$ & - & - & - \\
\hline $\begin{array}{l}\text { Limited to specific } \\
\text { diagnoses }\end{array}$ & 34.2 & 10.0 & $<0.001$ & 74.0 & 23.1 & $<0.001$ \\
\hline $\begin{array}{l}\text { Only readmissions because } \\
\text { of physician factors } \\
\text { considered avoidable }\end{array}$ & 9.5 & 17.9 & $<0.001$ & - & - & - \\
\hline Publication year $\geq 2000$ & 10.5 & 14.1 & $<0.001$ & - & - & - \\
\hline $\begin{array}{l}\text { Follow-up period for } \\
\text { readmissions of up to } 1 \mathrm{yr} \\
\text { after dischargeł }\end{array}$ & 9.0 & 20.9 & $<0.001$ & 36.8 & 59.4 & $<0.001$ \\
\hline $\begin{array}{l}>2 \text { sources of information } \\
\text { used to determine } \\
\text { avoidability of readmissions }\end{array}$ & 24.6 & 9.6 & $<0.001$ & - & - & - \\
\hline $\begin{array}{l}\text { Mostly teaching hospitals } \\
\text { in study }\end{array}$ & 8.7 & 53.4 & $<0.001$ & 20.8 & 76.4 & $<0.001$ \\
\hline Study from United States & 25.5 & 9.9 & $<0.001$ & - & - & - \\
\hline $\begin{array}{l}\text { Study from United Kingdom } \\
\text { or Ireland }\end{array}$ & 15.6 & 11.4 & $<0.001$ & - & - & - \\
\hline \multicolumn{7}{|c|}{$\begin{array}{l}\text { *This table summarizes the results of univariable and multivariable binomial regression models that measured the association of } \\
\text { study-level factors with the proportion of readmissions deemed avoidable. With the exception of the first factor (administrative } \\
\text { database study), all analyses excluded the three studies that used administrative databases alone. } \\
\text { tCompared with studies that excluded such patients or that did not specify patient type. } \\
\text { ‡Compared with studies that had a follow-up period of up to } 2.5 \text { months after discharge. }\end{array}$} \\
\hline
\end{tabular}


Criteria used in future studies need to focus on determining whether the readmission was preceded by an adverse event (i.e., a bad medical outcome due to medical care rather than the natural history of disease or bad luck); whether the adverse event could have been prevented; and whether the readmission would have occurred even without the adverse event or whether other factors were involved. In addition, future studies need to include a large number of readmissions in a broad spectrum of patients from multiple teaching and community hospitals; multiple sources of patient information between index admission and readmission on which decisions regarding avoidabililty are based; an explicit statement about which groups or factors contributing to readmissions are considered avoidable; at least three reviewers per readmission to judge avoidability; and the use of structural modelling methods such as the latent class model to measure the probability that patients truly had an avoidable readmission based on the judgments of reviewers.

\section{References}

1. Office of the Auditor General of Ontario. 2010 annual report discharge of hospital patients. Toronto (ON): Government of Ontario; 2010. p. 64-93. Available: www.auditor.on.ca/en /reports_en/en10/302en10.pdf (accessed 2011 Mar. 11).

2. Harrell FE. Multivariable modeling strategies. Regression modelling strategies. New York (NY): Springer; 2001. p. 53-86.

3. DerSimonian R, Laird N. Meta-analysis in clinical trials. Control Clin Trials 1986;7:177-88.

4. Higgins JP, Thompson SG, Deeks JJ, et al. Measuring inconsistency in meta-analyses. BMJ 2003;327:557-60.

5. Graham H, Livesley B. Can readmissions to a geriatric medical unit be prevented? Lancet 1983;1:404-6.

6. Popplewell PY, Chalmers JP, Burns RJ, et al. A review of early medical readmissions at the Flinders Medical Centre. Aust Clin Rev. 1984;11:3-5.

7. MacDowell NM, Hunter SA, Ludke RL. Readmissions to a Veterans Administration medical center. J Qual Assur 1985;7:20-3.

8. McInnes EG, Joshi DM, O'Brien TD. Failed discharges: setting standards for improvement. Geriatric Medicine. 1988;18:35-42.

9. Williams EI, Fitton F. Factors affecting early unplanned readmission of elderly patients to hospital. BMJ 1988;297:784-7.

10. Clarke A. Are readmissions avoidable? BMJ 1990;301:1136-8.

11. Vinson JM, Rich MW, Sperry JC, et al. Early readmission of elderly patients with congestive heart failure. J Am Geriatr Soc 1990;38:1290-5.

12. Frankl SE, Breeling JL, Goldman L. Preventability of emergent hospital readmission. Am J Med 1991;90:667-74.

13. Kelly JF, McDowell H, Crawford V, et al. Readmissions to a geriatric medical unit: Is prevention possible? Aging (Milano) 1992;4:61-7.

14. Gautam P, Macduff C, Brown I, et al. Unplanned readmissions of elderly patients. Health Bull (Edinb) 1996;54:449-57.

15. Haines-Wood J, Gilmore DH, Beringer TR. Re-admission of elderly patients after in-patient rehabilitation. Ulster Med J 1996; 65:142-4

16. Oddone EZ, Weinberger M, Horner M, et al. Classifying general medicine readmissions. Are they preventable? Veterans Affairs Cooperative Studies in Health Services Group on Primary Care and Hospital Readmissions. J Gen Intern Med 1996;11:597-607.

17. McKay MD, Rowe MM, Bernt FM. Disease chronicity and quality of care in hospital readmissions. J Healthc Qual 1997;19:33-7.

18. Experton B, Ozminkowski RJ, Pearlman DN, et al. How does managed care manage the frail elderly? The case of hospital readmissions in fee-for-service versus HMO systems. Am J Prev Med 1999;16:163-72.

19. Kwok T, Lau E, Woo J, et al. Hospital readmission among older medical patients in Hong Kong. J R Coll Physicians Lond 1999; 33:153-6.
20. Miles TA, Lowe J. Are unplanned readmissions to hospital really preventable? J Qual Clin Pract 1999;19:211-4.

21. Levy A, Alsop K, Hehir M, et al. Hospital readmissions. We'll meet again. Health Serv J 2000;110:30-1.

22. Madigan EA, Schott D, Matthews CR. Rehospitalization among home healthcare patients: results of a prospective study. Home Healthc Nurse 2001;19:298-305.

23. Halfon P, Eggli Y, van Melle G, et al. Measuring potentially avoidable hospital readmissions. J Clin Epidemiol 2002;55:573-87.

24. Munshi SK, Lakhani D, Ageed A, et al. Readmissions of older people to acute medical units. Nurs Older People 2002;14:14-6.

25. Sutton CDM. Leicestershire surgical readmissions survey. J Clin Excellence 2002;4:33-41.

26. Courtney ED, Ankrett S, McCollum PT. 28-Day emergency surgical re-admission rates as a clinical indicator of performance. Ann R Coll Surg Engl 2003;85:75-8.

27. Friedman B, Basu J. The rate and cost of hospital readmissions for preventable conditions. Med Care Res Rev 2004;61:225-40.

28. Jiménez-Puente A, Garcia-Alegria J, Gomez-Aracena J, et al. Readmission rate as an indicator of hospital performance: the case of Spain. Int J Technol Assess Health Care 2004;20:385-91.

29. Maurer PP, Ballmer PE. Hospital readmissions - Are they predictable and avoidable? Swiss Med Wkly 2004;134:606-11

30. Halfon P, Eggli Y, Pretre-Rohrbach I, et al. Validation of the potentially avoidable hospital readmission rate as a routine indicator of the quality of hospital care. Med Care 2006;44:972-81.

31. Kirk E, Prasad MK, Abdelhafiz AH. Hospital readmissions: patient, carer and clinician views. Acute Medicine. 2006;5:104-7.

32. Balla U, Malnick S, Schattner A. Early readmissions to the department of medicine as a screening tool for monitoring quality of care problems. Medicine 2008;87:294-300.

33. Goldfield NI, McCullough EC, Hughes JS, et al. Identifying potentially preventable readmissions. Health Care Financ Rev 2008;30:75-91.

34. Ruiz B, Garcia M, Aguirre U, et al. Factors predicting hospital readmissions related to adverse drug reactions. Eur J Clin Pharmacol 2008;64:715-22.

35. Stanley A, Graham N, Parrish A. A review of internal medicine re-admissions in a peri-urban South African hospital. S Afr Med J 2008;98:291-4.

36. Witherington EM, Pirzada OM, Avery AJ. Communication gaps and readmissions to hospital for patients aged 75 years and older: observational study. Qual Saf Health Care 2008;17:71-5.

37. Phelan D, Smyth L, Ryder M, et al. Can we reduce preventable heart failure readmissions in patients enrolled in a disease management programme? Ir J Med Sci 2009;178:167-71.

38. Shalchi Z, Saso S, Li HK, et al. Factors influencing hospital readmission rates after acute medical treatment. Clin Med 2009; 9:426-30.

39. Medicare Payment Advisory Commission. Report to the Congress: promoting greater efficiency in Medicare. Washington (DC): The Commission; 2007. p.107-8. Available: www.medpac .gov/documents/jun07_entirereport.pdf (accessed 2011 Mar. 11).

40. Rutjes AW, Reitsma JB, Coomarasamy A, et al. Evaluation of diagnostic tests when there is no gold standard. A review of methods. Health Technol Assess 2007:11:iii, ix-51.

41. Goetghebeur E, Liinev J, Boelaert M, et al. Diagnostic test analyses in search of their gold standard: latent class analyses with random effects. Stat Methods Med Res 2000;9:231-48.

42. Formann AK, Kohlmann T. Latent class analysis in medical research. Stat Methods Med Res 1996;5:179-211.

Affiliations: From the Faculty of Medicine (van Walraven, Forster), University of Ottawa, Ottawa, Ont.; the Ottawa Health Research Institute (van Walraven, Bennett, Jennings, Forster), Ottawa, Ont.; the Institute for Clinical Evaluative Sciences (van Walraven, Austin, Forster), Toronto, Ont.; and the Department of Health Management, Policy and Evaluation, and the Dalla Lana School of Public Health (Austin), University of Toronto, Toronto, Ont.

Contributors: All of the authors made substantial contributions to the conception and design of the study and the acquisition, analysis and interpretation of the data. Carl van Walraven, Peter Austin and Alan Forster drafted the article; all of the authors revised the manuscript critically for important intellectual content and approved the final version submitted for publication. Carl van Walraven had full access to all of the data in the study; he takes responsibility for the integrity of the data and the accuracy of the data analysis.

Funding: This study was supported by the Department of Medicine, University of Ottawa, Ottawa, Ont. 


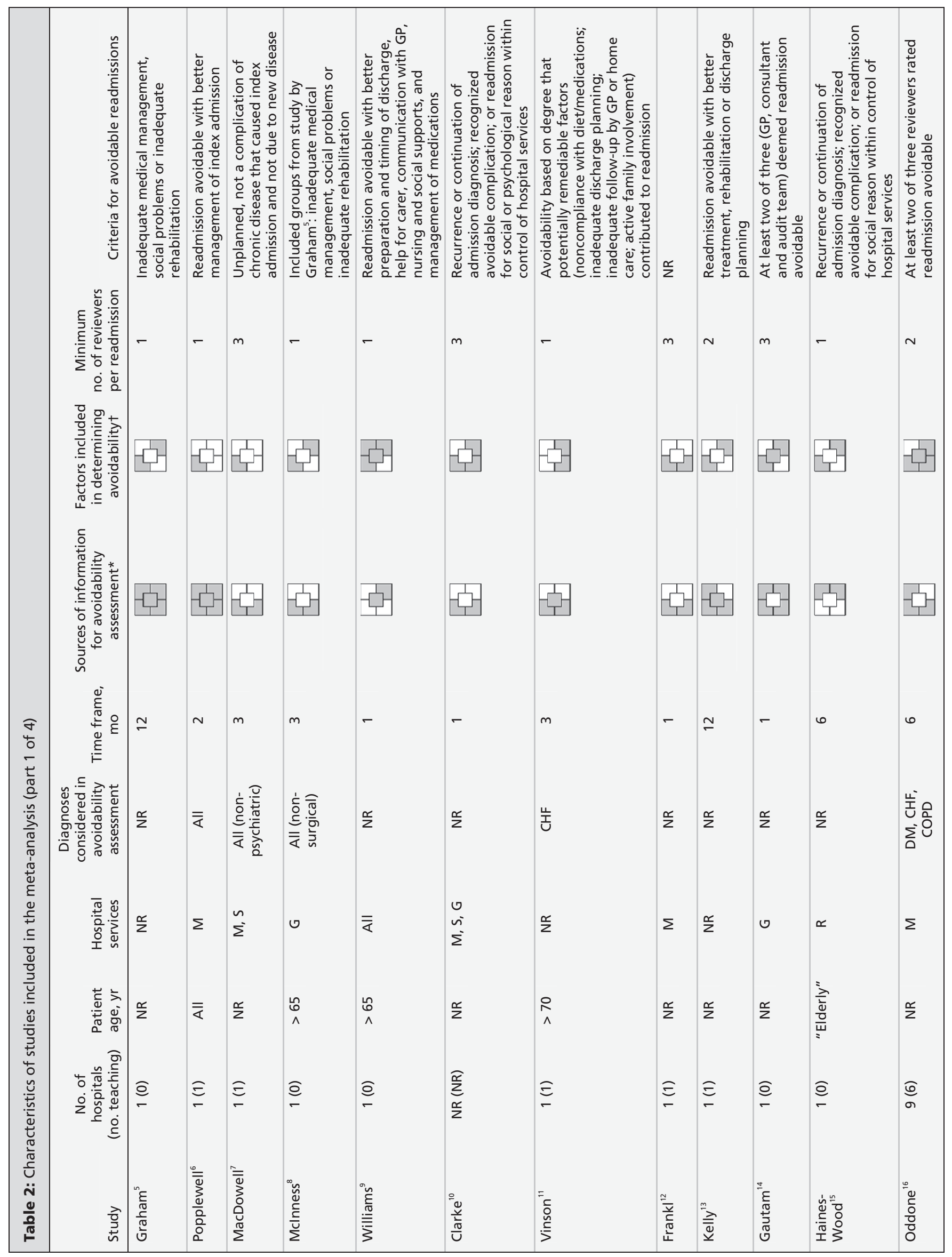




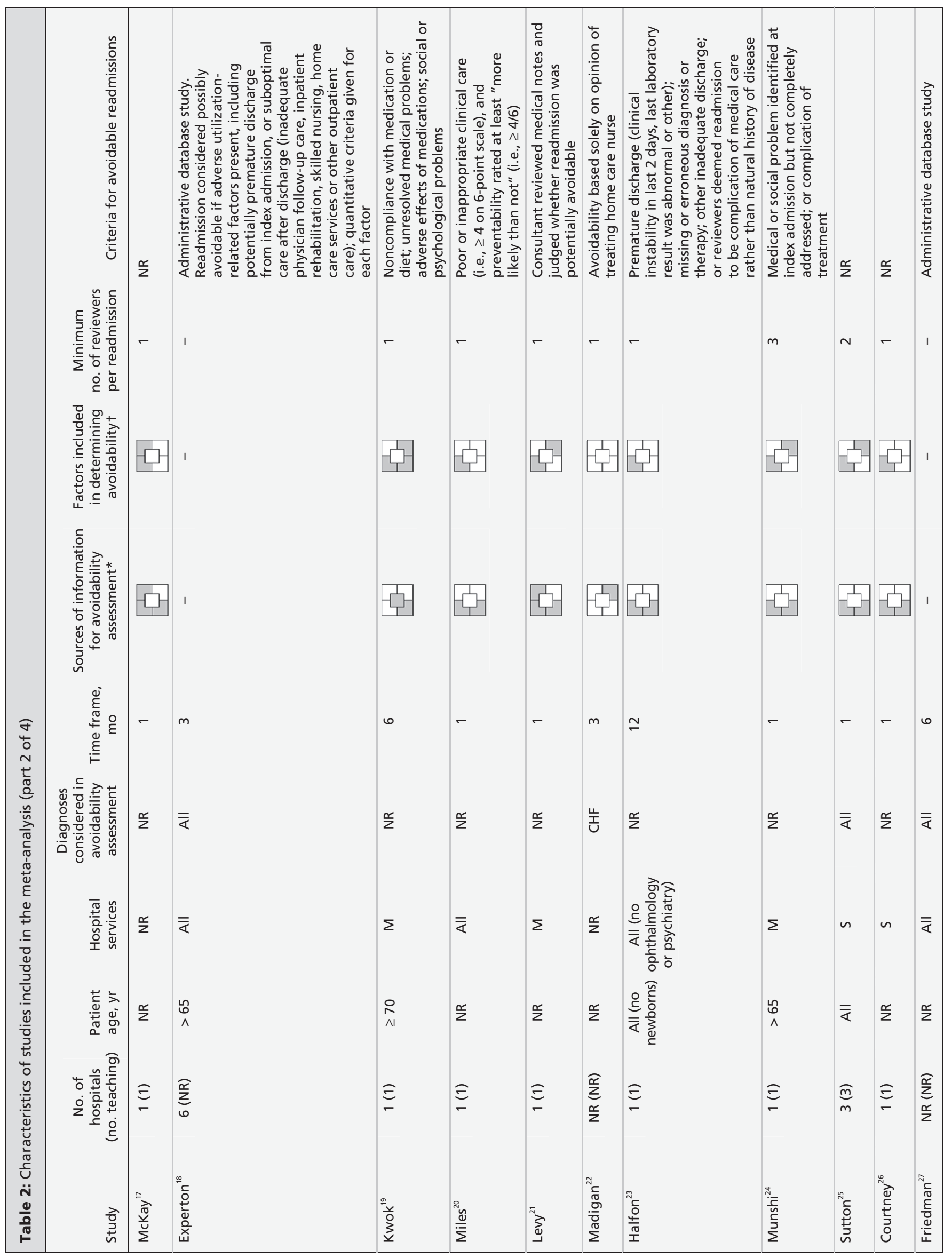




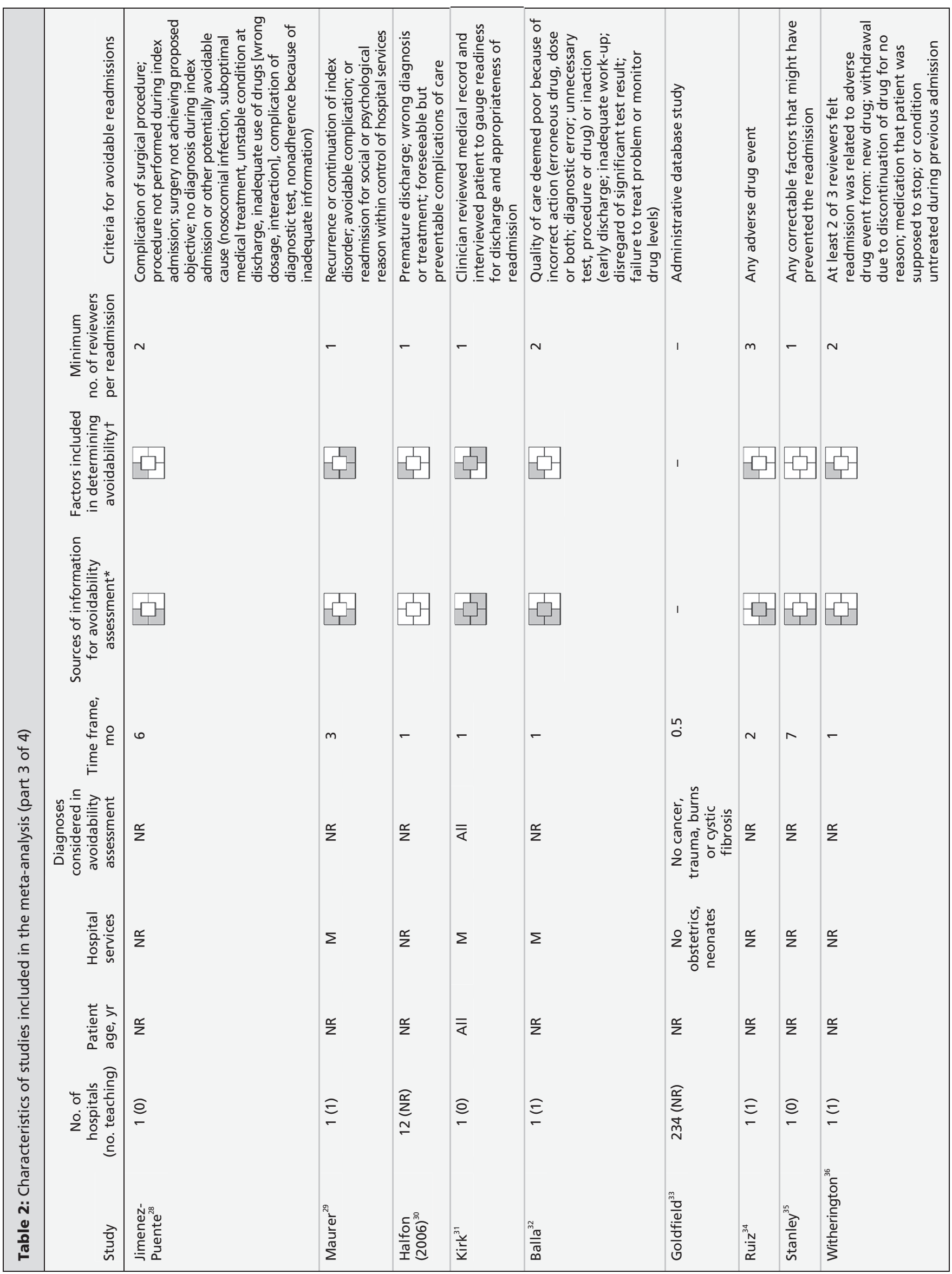




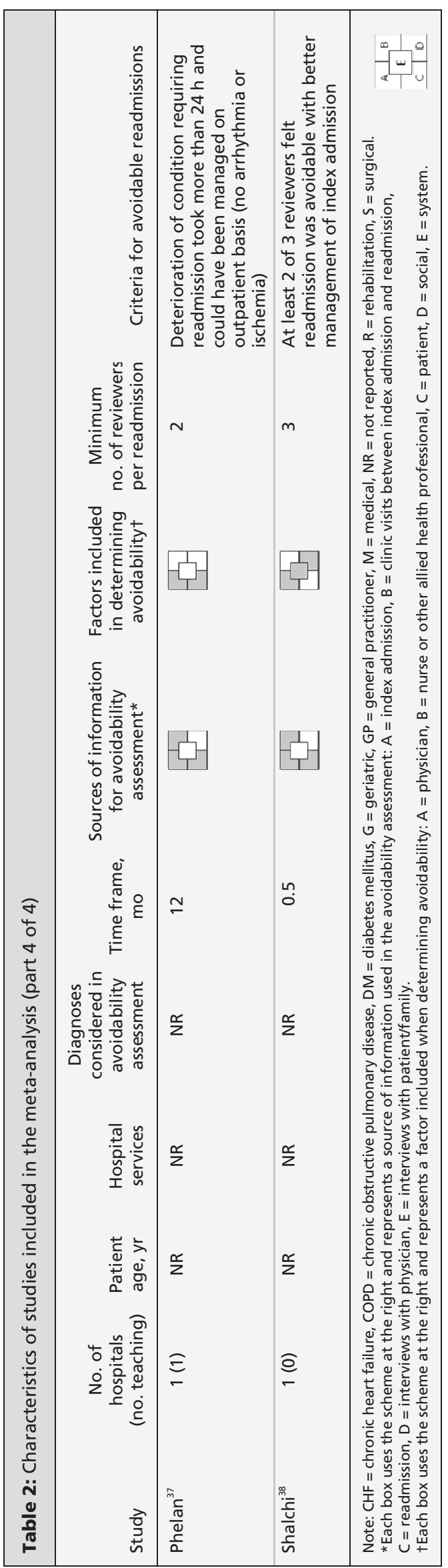

